\title{
Grèce-Roumanie : héritages communs, regards croisés
}

\section{Cécile Folschweiller et Georges Kostakiotis}

\section{(2) OpenEdition}

\section{Journals}

Édition électronique

URL : https://journals.openedition.org/ceb/5227

DOI : $10.4000 /$ ceb.5227

ISSN : 2261-4184

Éditeur

INALCO

Référence électronique

Cécile Folschweiller et Georges Kostakiotis, « Grèce-Roumanie : héritages communs, regards croisés », Cahiers balkaniques [En ligne], 42 | 2014, mis en ligne le 06 juin 2014, consulté le 07 juillet 2021. URL : http://journals.openedition.org/ceb/5227 ; DOI : https://doi.org/10.4000/ceb.5227

Ce document a été généré automatiquement le 7 juillet 2021.

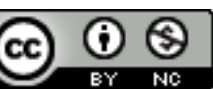

Cahiers balkaniques est mis à disposition selon les termes de la Licence Creative Commons Attribution - Pas d'Utilisation Commerciale 4.0 International. 


\title{
Grèce-Roumanie : héritages communs, regards croisés
}

\author{
Cécile Folschweiller et Georges Kostakiotis
}

1 La Roumanie et la Grèce, aux deux extrémités de la péninsule balkanique, l'une imprégnée du monde de l'Europe centrale, l'autre du monde méditerranéen, partagent un héritage commun abondant, nourri par l'histoire. Sur ce vaste sujet déjà bien exploré, il ne saurait être question ici de trancher des débats de spécialistes ni de faire une présentation exhaustive. Enclencher une dynamique de travail collectif et interdisciplinaire en provoquant la rencontre de collègues proches ou lointains travaillant sur des questions gréco-roumaines afin d'ouvrir de nouveaux chantiers de recherche, voilà l'ambition de la Journée d'étude organisée à l'INALCO le 24 mai 2013 et consacrée aux liens unissant ces deux peuples, ces deux histoires, ces deux cultures, dont les contributions sont regroupées dans ce dossier des Cahiers balkaniques. Repartir de données simples et de constats connus - héritages communs antiques, byzantins, orthodoxes, ottomans et balkaniques, communautés grecques des Principautés et valaques en pays grecs, gouvernement des princes phanariotes, transferts culturels par le biais de la langue et des livres, destins historiques qui se croisent, inspirations littéraires qui se nourrissent réciproquement - tout en refusant de se restreindre à des thématiques ou à des périodes spécifiques, du moins pour cette première journée, devait permettre de laisser libre cours aux préoccupations actuelles des chercheurs travaillant sur cet espace, de faire un tour d'horizon des travaux en cours et des chantiers à ouvrir ou à approfondir. Les thématiques et les approches - historiques, littéraires, politiques, culturelles - furent effectivement riches et variées.

2 La bibliographie sur le sujet est longue, tout comme la tradition de recherche existante dans les deux pays, conscients de ce passé partagé. C'est tout l'intérêt de l'article de synthèse proposé par Anna Tabaki qui offre, en ouverture, un bilan des travaux de recherche menés dans les deux pays tout au long du $\mathrm{xx}^{\mathrm{e}}$ siècle, comme autant de «regards croisés» sur les thématiques essentielles - tradition byzantine et postbyzantine, réception des idées des Lumières et formation de l'esprit moderne, place de la langue grecque dans les cultures des pays balkaniques, éducation, littérature, en 
particulier dans le monde phanariote et de la diaspora grecque en pays roumains - de Nicolae Iorga à Ariadna Camariano-Cioran, de C. Th. Dimaras à Alexandru DuŢu, pour n'en citer que quelques-uns. Les nouvelles perspectives de la recherche actuelle évoquées par l'auteure à la fin de son article se trouvent illustrées par certaines des contributions qui suivent.

3 Le sujet traité par Lidia Cotovanu, effectivement "moins connu», en amont de la période phanariote, et recourant tant à l'analyse quantitative (dénombrement des individus dans les sources) que qualitative (analyse des patronymes, des liens de parentés, des réseaux professionnels et des traditions de donations religieuses aux monastères), confirme la part majoritaire des Grecs dans l'émigration sud-danubienne en Valachie et Moldavie entre les $\mathrm{XVI}^{\mathrm{e}}$ et $\mathrm{XVII}^{\mathrm{e}}$ siècles tout en affinant et relativisant les catégories: derrière le qualificatif de "Grec» se cachent des identités multiples, brouillées et instables qui peuvent contribuer à expliquer des situations ultérieures apparemment paradoxales, comme la participation d'allogènes grécophones à certaines révoltes anti-grecques dans les Principautés.

4 Avec son étude sur la Cour nouvelle ou «Brûlée » de Bucarest, le palais disparu des princes phanariotes de Valachie, Tudor Dinu donne un exemple d'histoire locale et de ce qu'Anna Tabaki appelle la «revalorisation de la personnalité dans l'herméneutique historiographique». Les sources écrites et les résultats de fouilles archéologiques permettent à l'auteur d'y reconstituer le tableau, la fresque courte, mais dense de la vie et des événements qui animèrent ce lieu, de sa construction, en 1774 par Alexandre Ypsilanti, à sa destruction, en décembre 1812, par un incendie qui s'inscrivait dans la suite d'autres catastrophes. Les circonstances de l'assassinat du prince Constantin Hangerli par un envoyé des Ottomans, dont le palais fut le cadre en 1799, illustrent la brutalité des rapports de force entre les princes phanariotes grecs et d'un côté, le sultan de la Porte, de l'autre, la population roumaine.

5 Les quatre articles suivants abordent la question gréco-roumaine sous l'angle du « regard de l'autre » et traitent des représentations, pleines de jugements de valeur, qui ne manquent pas de se développer lorsque deux mondes sont aussi longtemps confrontés l'un à l'autre et pris dans des rapports de domination - culturelle, politique, économique. Jacques Bouchard examine précisément l'une des origines assignables de la «mauvaise réputation" que traînent derrière eux les Phanariotes: l'Essai sur les Phanariotes de Marc-Philippe Zallony publié en France en 1824 et réédité en 1830 sous un titre explicitant mieux encore que le premier leur caractère négatif: Traité sur les princes de la Valachie et de la Moldavie, sortis de Constantinople, connus sous le nom: Fanariotes; ou exposé de leur influence dans l'Empire ottoman contre les Grecs, et du danger de les admettre dans la direction des affaires de la Grèce régénérée. C'est ce texte qui vulgarise le terme en français avec sa connotation négative et, par répercussion, également dans les espaces grecs et roumains, l'origine grecque de l'auteur ne donnant que plus de force à sa thèse. L'ouvrage est effectivement traduit rapidement en grec, les commentaires des traducteurs appuyant fortement la thèse. Quant aux élites roumaines, souvent francophones, elles n'ont pas attendu la première traduction, plus tardive (1897), pour s'approprier des formules qui correspondaient si bien à leur expérience. Les différentes éditions des traductions grecques et roumaines sont autant d'occasions de relancer le débat sur le rôle des Phanariotes dans les deux pays, suscitant également des défenses et apologies aussi fortes que les condamnations dont cette communauté fait l'objet, avant de faire l'objet d'études plus critiques et distanciées. 
6 Cécile Folschweiller analyse ensuite les formes prises par cette vision négative dans le discours idéologique et nationaliste roumain de la deuxième moitié du xix siècle où le Grec partage avec le Juif la position de la minorité détestée, pour des raisons parfois proches, mais dont il importe de pointer les différences. Alors que l'historien Nicolae Bălcescu fait de l'épisode phanariote une phase de la marche dialectique de l'histoire roumaine, Mihai Eminescu et Dumitru Drăghicescu confondent de plus en plus, dans leurs textes à dimension raciste, le phanariote avec le Grec, accusé d'avoir introduit chez les Roumains une perversion du caractère qui expliquerait une grande partie des malheurs du pays, quand il est reproché aux Juifs une domination essentiellement économique. Le cliché phanariote se trouve également mobilisé, notamment par Eminescu et certains conservateurs des années 1880, pour être retourné contre les pratiques politiciennes du parti libéral.

7 La vision partielle et partiale des Phanariotes en Roumanie a trouvé dans la littérature aussi un vaste champ pour s'exprimer, voire se constituer en mythe, comme le montre la synthèse d'Andreia Roman. Des célèbres Parvenus d'hier et d'aujourd'hui de N. Filimon inaugurant la tradition romanesque roumaine à la renaissance du thème sous le communisme, les Phanariotes offraient de riches potentialités littéraires : un exotisme oriental aux ancrages aussi bien grecs qu'ottomans, des épisodes plus ou moins historiques mêlant caricature bouffonne et violence tragique, intrigues financières et cruauté despotique, mais aussi le moyen d'affirmer par contraste un sain roumanisme ou bien de suggérer une victimisation du peuple, conforme à une représentation classique de l'histoire nationale. Sous Ceauşescu, le personnage romanesque du phanariote peut s'enrichir d'une dimension subversive lorsque l'auteur laisse la porte ouverte à des comparaisons avec le Conducator ou encore renvoyer peut-être à l'ambivalente position de l'homme du système qu'est l'écrivain Eugen Barbu, dans le contexte d'une fin de régime décadente.

8 Le regard de l'autre prend une tout autre couleur lorsqu'il émane d'ailleurs, d'un tiers extérieur aux deux espaces considérés et c'est tout l'intérêt de celui de Karl Dieterich exhumé par Marie-Elisabeth Mitsou, regard de comparatiste allemand chez qui la comparaison tourne à l'avantage des Roumains. «Cet éloge de la Roumanie prononcé par un ami des Grecs ", pour reprendre les mots de l'auteure, n'aurait pas manqué de flatter les Roumains, mais aussi de les surprendre. Car c'est du point de vue de leur avancement dans la modernité qu'ils sont mis par l'helléniste allemand, en 1905, audessus des Grecs, eux, les Roumains, qui ne cessent de courir après leur retard à rattraper sur la culture occidentale. Il n'est plus question ici de revenir sur le passé et l'héritage phanariote, mais de considérer, en plein contexte de compétition des nations, les évolutions présentes et les orientations prises par chacune des deux cultures. Or il semble à Dieterich que l'esprit critique et réformateur, le rejet du nationalisme étroit hérité des vieux romantismes du XIX siècle et le souci d'une langue moderne défendus par Maiorescu en Roumanie devraient servir de modèle aux Grecs, chez qui il rejette le philhellénisme classique tourné vers l'illusoire pureté antique. Le Maiorescu grec aurait pu être Jean Psichari, linguiste grec de Paris, enseignant à l'École des Langues orientales et défenseur de la langue démotique, si sa stratégie culturelle avait été plus ouverte et si les conditions de sa réception avaient été remplies dans son pays d'origine, analyse M.-E. Mitsou, poursuivant la réflexion comparatiste engagée par Karl Dieterich. Mais ce n'était pas le cas, les réflexions intellectuelles, linguistiques et littéraires des démoticistes se trouvant en décalage avec les politiques institutionnelles, 
tout comme, à une autre échelle, le concept de "culture balkanique " auquel aboutissait l'auteur allemand était en profond décalage avec le contexte historique régional, moins de dix ans avant les guerres balkaniques.

Des guerres balkaniques de 1912-1913 à la conférence balkanique de 1939, d'une guerre régionale à l'orée d'une guerre bientôt mondiale, la Grèce et la Roumanie sont entraînées ensemble dans les soubresauts violents de l'Europe de la première moitié du $\mathrm{xx}^{\mathrm{e}}$ siècle. Le travail d'historienne d'Alkisti Sofou et l'analyse littéraire de Georges Kostakiotis se rencontrent opportunément à Bucarest au printemps 1939 pour apporter deux éclairages tout à fait complémentaires sur le contexte et l'atmosphère de ces mois précédant le déclenchement de la guerre. On y voit l'unité de l'Entente balkanique mise à mal par les divergences et les politiques d'accords bilatéraux menées par certains de ses membres alors qu'aussi bien les prises de parole de Ioannis Metaxás que les mémoires du ministre roumain Grigore Gafencu témoignent de la nécessité d'une politique commune de sécurité et d'indépendance à l'égard des grandes puissances. En écho aux mots d'enthousiasme que Metaxás prononce à la conférence de presse finale, «Tout est bien qui commence bien. Depuis notre arrivée dans la splendide capitale de la Roumanie, l'ambiance de notre Conférence était belle comme ce temps radieux », le poème que Georges Séféris écrit suite à ses deux visites à Bucarest en février et mai 1939 (la première à l'occasion justement de cette Conférence) résonne de manière autrement plus sombre et prophétique. Le cheval de Moldovalachie se réfère à la statue équestre du roi Carol $\mathrm{I}^{\mathrm{er}}$ qui vient d'être inaugurée sur la place du Palais Royal par Carol II pour commémorer les 100 ans de la naissance du premier souverain roumain, statue sur laquelle donne sa fenêtre de l'Athénée Palace. Ce symbole de gloire et de triomphe, le poète grec le transforme en évocations parfois violentes et crues de la mort, de la lutte, de la défaite annoncée, de la fatigue, de la décadence, de la précarité du monde et de ses institutions humaines illusoires, par un réseau d'images et de symboles qui unissent la Grèce et la Roumanie dans ce destin commun.

10 Histoire et littérature, enfin, s'unissent dans le texte de Catherine Durandin pour clore ce volume par un voyage très personnel entre la Grèce antique et la Roumanie contemporaine, entre le poème Ulysse de Benjamin Fondane et son propre dernier roman, situé à Constanţa - l'ancienne Tomis grecque sur les bords de la mer Noire - où les deux thématiques de l'exil et de la tragédie, l'exil du Juif Fondane fuyant la Roumanie antisémite et la tragédie du deuil pour la mère et l'amante de Julien dans le roman, dévoilent d'autres liens, affinités et destinées convergentes entre les espaces grecs et roumains.

11 Ce parcours gréco-roumain qui s'est tissé à partir des propositions de contributions et a trouvé son unité dans les échanges de cette journée ouvre d'autres pistes. La bibliographie est déjà vaste, comme nous le rappelions, mais elle reste réduite sur la période plus récente, pendant laquelle la complexité des évolutions historiques et culturelles a peut-être plus mis en évidence les différences et divergences, Grèce et Roumanie poursuivant chacune leur destin national. Mais autant la perpétuation des héritages communs et des histoires mêlées - celle des communautés grecques et valaques dans les Balkans, celle des relations politiques entre les deux États - que la poursuite des échanges entre les deux cultures - en littérature, dans les arts et dans les traditions populaires - continuent de lier les deux pays, au sein, qui plus est, de la construction d'une Europe élargie. D'autres rencontres et, nous l'espérons, un second volume publié, devraient venir poursuivre cette initiative de recherche. 


\section{AUTEURS}

CÉCILE FOLSCHWEILLER

INALCO 